\title{
The importance of parental beliefs and support for pedometer-measured physical activity on school days and weekend days among Canadian children
}

Kerry A Vander Ploeg ${ }^{1}$, Stefan Kuhle², Katerina Maximova', Jonathan McGavock ${ }^{3}$, Biao Wu ${ }^{1}$ and Paul J Veugelers ${ }^{1 *}$

\begin{abstract}
Background: Parental influences are essential to the behaviours and physical activity of their children. Our study aimed to determine if parental beliefs and support are associated with children's pedometer measured physical activity levels on school days and weekend days.

Methods: In the spring of 2009 and 2011, we analyzed cross-sectional data from 1,355 grade five students and parents in 30 schools in Alberta, Canada. Parents reported how much they care about exercising, how much they encourage their child to be physically active, and how frequently they engage in physical activities with their child. Physical activity was assessed from step counts obtained from time-stamped pedometers collected over nine consecutive days.

Results: Increased parental encouragement was positively associated with boys' and girls' physical activity on school days (Boys: beta $=1373,95 \%$ Cl: 606, 2139; Girls: beta $=632,95 \% \mathrm{Cl}: 108,1155$ ) and girls' physical activity on weekend days (beta $=997,95 \% \mathrm{Cl}: 130,1864)$. Increased parental care was positively associated with boys' physical activity on weekend days (beta $=1381,95 \% \mathrm{Cl}: 85,2676$ ). Increased parental support and engagement was associated with an additional 632-1381 steps/day for children in this study.

Conclusions: Parental care, encouragement and engagement are associated with physical activity levels of children 10-11 years of age. Policy makers and researchers should consider the importance of targeting parents when designing strategies to promote physical activity in children. This is particularly relevant to weekends and holidays when children's activity levels are low.
\end{abstract}

Keywords: Physical activity, Pedometer, Childhood obesity, Public health, Health promotion

\section{Background}

Regular physical activity is associated with an array of health benefits for children [1]. Unfortunately, most children in Canada are not sufficiently active. Currently, only $7 \%$ of boys and $3 \%$ of girls accumulate the recommended 13,500 steps per day at least 6 days a week [2]. We have previously demonstrated that these trends are significantly worse on weekend days, relative to weekdays [3]. These trends are concerning as low levels of physical activity during childhood contribute to obesity

\footnotetext{
* Correspondence: paul.veugelers@ualberta.ca

${ }^{1}$ School of Public Health, University of Alberta, Edmonton Alberta, Canada Full list of author information is available at the end of the article
}

and comorbid conditions in adulthood [4]. As such, increasing children's physical activity levels, particularly on weekend days, continues to be a priority for improving child health outcomes.

It is well established that parental influences are essential to the behaviours and physical activity of their children [5-7]. Children's physical activity levels have been shown to be greater when parents are active, encourage them to be active, and engage in activities with them [6,8-11]. Reviews demonstrate that childhood is an important time to establish healthy behaviours given that behaviours established and practiced in childhood track into adulthood [12,13]. However, as children spend 
substantial time at school, parents may have more opportunities to influence children's physical activity on weekend days than on school days. To our knowledge, the importance of parental beliefs and support as a correlate of children's weekend day physical activity has never been studied.

To address this knowledge gap, we relied on recently collected cross-sectional data to test the hypothesis that parental beliefs and support for physical activity are positively associated with physical activity levels in grade five students on school and weekend days. We also hypothesized that this association is distinct for school days and weekend days.

\section{Methods}

\section{Study design/setting}

Raising healthy Eating and Active Living Kids in Alberta (REAL Kids Alberta) is a population-based study of grade five children and their parents in the Canadian province of Alberta. In 2008, the REAL Kids Alberta survey included 148 randomly selected schools from across Alberta as described elsewhere [14]. In 2009, we selected and invited a convenient sample of 20 of the 148 schools, located in the city of Edmonton and surrounding areas, to participate in an additional survey that included objective measures of physical activity. We also invited grade five students from 10 schools participating in the Alberta Program Promoting active Living and healthy Eating in Schools (APPLE Schools) [15]. We repeated data collection among grade five students and parents in 2011 from the same schools that participated in 2009. In 2009 and 2011 combined, we sent 2,502 parent consent forms and surveys home with students for their parents to complete and return to school; 2,045 (81.7\%) home surveys were returned, 2,028 (99.2\%) students received parental consent to participate. Student assent to participate was obtained from 1,991 (98.2\%) children, and 1,977 (99.3\%) children completed student surveys, resulting in an overall participation rate of $79.0 \%$. Pedometers were distributed to the 1,991 students with parent consent and student assent, 1,783 pedometers were returned, providing crude hourly step counts; 210 (10.5\%) pedometers were lost or malfunctioned. The Health Research Ethics Board of the University of Alberta approved this study, including data collection and parental informed consent forms.

\section{Assessment of parental beliefs and support}

The parent survey included three validated questions related to beliefs and support that were adapted from the activity-related parenting practices scale by Davison et al. [16]. These included: 1) how much do you personally care about staying fit and exercising (a little bit; quite a lot; very much); 2) to what extent do you encourage your grade five child to be physically active (a little bit; quite a lot; very much); and 3) how often do you or another parent/guardian usually engage in physical activity together with your child (less than 1 time/ week; 1-3 times/week; 4 or more times/week). The questionnaires we used are available on the project's website: http://www.REALKidsAlberta.ca.

\section{Assessment of physical activity}

We used Omron HJ-720ITC (Ontario, Canada) pedometers to measure physical activity objectively. This pedometer records steps hourly, automatically resets at midnight, and can store data for 42 days. Further rationale for selecting this pedometer are described in detail elsewhere [3]. The accuracy and validity of the Omron pedometer has been demonstrated under various conditions [17-19]. Students wore pedometers for nine consecutive days on their right hip directly in line with their right knee during all waking hours unless showering, swimming, or taking part in activities in which an adult deemed it unsafe to wear. Pedometer recordings from the first and ninth days were not considered as, on these days, the students started or ended wearing the pedometers, and thus recordings are not available for the full day. Students also kept a diary of their daily activities, including the duration of each activity and whether or not the pedometer was worn (available at: www.REALKidsAlberta.ca). Trained evaluation assistants returned to schools on the ninth day to collect pedometers and download data to computers. Pedometer recordings were stratified into school day (Monday-Friday) and weekend day (Saturday, Sunday, and holidays) categories.

\section{Confounding variables}

Evaluation assistants measured children's standing height to the nearest $0.1 \mathrm{~cm}$ using stadiometers (Seca-Stadiometer, Germany) and body weight to the nearest $0.1 \mathrm{~kg}$ on calibrated digital scales (Health-o-meter, IL, USA). Children removed their shoes for both measurements. Body Mass Index (BMI) was calculated as $\mathrm{kg} / \mathrm{m}^{2}$. Overweight was defined using the International Obesity Task Force BMI cut-off point established for children and youth [20]. The cut-off point is based on the health-related adult definition of overweight ( $\mathrm{BMI} \geq 25)$, but is adjusted to specific age and sex categories for children. Analyses were adjusted for the confounding potential of parental educational attainment, household income, and year of data collection.

\section{Data processing}

For our analyses we only considered pedometer recordings when worn for a minimum of 8 hours per day [21]. Additionally, we required pedometer recordings on at least two school days and one weekend day (weekend 
and/or holiday) [22]. When these conditions were met, students' pedometer-measured steps were complemented with step-equivalents of non-ambulatory and nonwear time activities recorded in students' activity diaries. Briefly, we assigned each activity recoded in activity diaries a youth-specific metabolic equivalent task (MET) unit [23]. Next, we categorized activities by intensity (i.e., moderate, moderate-to-vigorous, vigorous) $[24,25]$ and assigned a step per minute value to each category [26]. Adult METs units were used when youth specific values were not available [24]. When students forgot to wear their pedometer and complete their activity diary, we imputed information from the same hour (s) on other randomly selected valid days. Steps were only imputed within an individual and within school days and weekend days. This method of imputation has been shown to replace data more accurately than traditional group-centered methods that replace missing data with the group mean [27]. These procedures are described in further detail elsewhere [3].

In 2009 and 2011 combined, we had information of pedometer step counts and parental reporting of physical activity-related beliefs and support for 717 girls and 638 boys.

\section{Data analyses}

T-tests and chi-square tests were used to test for data collection year and sex differences. Because observations of students are clustered within schools, we applied random effects models with students nested in schools. For each of the parent belief and support variables, we first applied univariable linear regression models to determine their associations with girls' and boys' step-counts taken on weekend days and on school days. Second, we applied multivariable linear regression models to adjust for the confounding potential of parental educational attainment, household income, and year of data collection (referred to as Model 1). Last, we considered parent beliefs and support variables simultaneously while adjusting for the above confounders to quantify their independent importance for children's step-counts (referred to as Model 2). For each of the parent belief and support variables we used the middle response category as the reference group for analyses.

In a combined analysis, we used an interaction term (defined as the product of school day/weekend day and the parent belief and support variables) in the adjusted linear regression models to quantify the differential effect of beliefs and support on physical activity during school days versus weekend days.

Missing values for parental education attainment and household income were treated as separate covariate categories however we do not present their estimated values. We used Stata Version 12 (Stata Corp, TX USA) to perform the statistical analyses.

\section{Results}

Participant characteristics are reported in Table 1. The average daily step count was higher on school days than on weekend days $(12,868 \pm 4006$ vs. $11763 \pm 6636$ steps/ day $\mathrm{p}<0.001)$. Boys achieved significantly more steps per day than girls on school days $(13844 \pm 4424$ vs. $12000 \pm 3366 \mathrm{p}<0.001)$ and on weekend days $(12716 \pm$ 7488 vs. $10914 \pm 5645 \mathrm{p}<0.001)$. Parents also reported to encourage boys to be physically active significantly more than girls $(\mathrm{p}<0.001)$. There were no statistically significant differences in the data collected in 2009 and 2011.

Table 1 Characteristics of grade five students participating in the study

\begin{tabular}{|c|c|c|}
\hline & \multicolumn{2}{|c|}{ Mean \pm SD/Prevalence } \\
\hline & Girls $(n=717)$ & Boys $(n=638)$ \\
\hline Age & $10.9 \pm 0.4$ & $10.9 \pm 0.4$ \\
\hline BMI of child ${ }^{*}$ & $19.1 \pm 3.5$ & $19.7 \pm 4.4$ \\
\hline Overweight (\%) & 29.2 & 34.6 \\
\hline Obese $(\%)^{*}$ & 7.5 & 10.8 \\
\hline \multicolumn{3}{|l|}{ Physical activity ${ }^{1}$} \\
\hline School day ${ }^{*}$ & $12,000 \pm 3,366$ & $13,844 \pm 4,424$ \\
\hline Non-school day ${ }^{*}$ & $10,914 \pm 5,645$ & $12,716 \pm 7,488$ \\
\hline
\end{tabular}

Parent cares about staying fit and exercising

A little bit

Quite a lot

Very much

Parent encourages their child

to be physical activity

A little bit

Quite a lot

Very much

Parent engages in physical activity with their child

$$
\begin{aligned}
& <1 \text { time/week } \\
& 1-3 \text { times/week }
\end{aligned}
$$

$\geq 4$ times/week

Parental education attainment

$\begin{array}{lll}\text { Secondary or less } & 26.7 & 22.4 \\ \text { College } & 42.0 & 40.5 \\ \text { University and graduate } & 31.3 & 37.1 \\ \text { Household income (\$) } & & 19.2 \\ <50,000 & 21.5 & 14.3 \\ 50,001-75,000 & 15.9 & 17.3 \\ 75,001-100,000 & 17.4 & 49.3 \\ >100,001 & 45.3 & \end{array}$

1- pedometer-measured steps adjusted for non-ambulatory activities, non-wear time activities, and missing data.

* - considered statistically significant at $\mathrm{P}<0.05$. 
Girls

On school days, increased parental encouragement of physical activity, and increased parental engagement in physical activity together were significantly and positively associated with girls' daily step counts (Table 2: Model 1). Girls whose parents encouraged physical activity "very much" took an additional 632 (95\% CI: 108, 1155) steps per day on school days relative to girls whose parents encouraged them "quite a lot". Additionally, on school days, girls whose parents engaged in physical activity with them more than four times per week achieved an additional 890 (95\% CI: 67, 1712) steps per day relative to girls whose parents engaged in physical activity with them one to three times per week. On weekend days, increased parental encouragement of physical activity was the only positive association with girls' daily steps counts $(\beta=997,95 \% \mathrm{CI}$ : 130,1864$)$ that appeared to be statistically significant. Girls whose parents encouraged them "very much" to be physically active took an additional 997 (95\% CI: 130, 1864) steps per day on weekend days than girls whose parents encouraged them "quite a lot". Model 2 of Table 2 reveals that the three parental behaviours (parental care for staying fit and exercising, parental encouragement and parental engagement) are correlated such that none of the three behaviours has a statistically significant effect on girls' step counts over and above that of the other two behaviours.

\section{Boys}

On school days, increased encouragement of physical activity was associated with daily step counts. This association was statistically significant (Table 3). Boys whose parents encouraged physical activity "very much" took an additional 1373 (95\% CI: 606, 2139) steps per day on school days relative to boys whose parents encouraged physical activity "quite a lot". This association was independent of parental care for staying fit and exercising and parental engagement in physical activity (Table 3: Multivariable Model 2). On weekend days, increased parental care about staying fit and exercising was positively associated with boys' daily step counts (Table 3 ). Boys whose parents reported to care "very much" about staying fit and exercising took an additional 1381 (95\% CI: 85, 2676) (Table 3) steps per day on weekend days relative to boys whose parents reported to care "quite a lot". Also, on weekend days, decreased parental engagement in physical activity was negatively associated with boys' daily step counts (Table 3). That is, boys whose parents engaged in physical activity with them less than once per week took 1367 fewer steps per day on weekend days relative to boys whose parents engaged in physical activity with them one to three times per week (95\% CI: -2643, -90). This association was independent of parental care for staying fit and exercising and parental encouragement (Table 3: Multivariable Model 2).

Table 2 The association (beta coefficient and $95 \%$ confidence interval) of parent belief and support with grade five girls' physical activity ${ }^{1}$ on school days and weekend days

\begin{tabular}{|c|c|c|c|c|c|c|c|c|c|c|c|c|}
\hline & \multicolumn{6}{|c|}{ School days } & \multicolumn{6}{|c|}{ Weekend days } \\
\hline & \multirow{2}{*}{\multicolumn{2}{|c|}{ Univariable }} & \multicolumn{4}{|c|}{ Multivariable } & \multirow{2}{*}{\multicolumn{2}{|c|}{ Univariable }} & \multicolumn{4}{|c|}{ Multivariable } \\
\hline & & & \multicolumn{2}{|c|}{ Model $1^{2}$} & \multicolumn{2}{|c|}{ Model $2^{3}$} & & & \multicolumn{2}{|c|}{ Model $1^{2}$} & \multicolumn{2}{|c|}{ Model $2^{3}$} \\
\hline & $\beta$ & $(95 \% \mathrm{Cl})$ & $\beta$ & $(95 \% \mathrm{Cl})$ & $\beta$ & $(95 \% \mathrm{Cl})$ & $\beta$ & $(95 \% \mathrm{Cl})$ & $\beta$ & $(95 \% \mathrm{Cl})$ & $\beta$ & $(95 \% \mathrm{Cl})$ \\
\hline \multicolumn{13}{|c|}{ Care staying fit $\&$ exercising } \\
\hline A little bit & -506 & $-1151,140$ & -416 & $-1057,224$ & -238 & $-896,421$ & -745 & $-1806,316$ & -605 & $-1665,454$ & -471 & $-1561,619$ \\
\hline Quite a $\operatorname{lot}^{4}$ & 0 & - & 0 & - & 0 & - & 0 & - & 0 & - & 0 & - \\
\hline Very much & 347 & $-214,907$ & 339 & $-218,897$ & 34 & $-576,644$ & 605 & $-315,1526$ & 613 & $-309,1535$ & 170 & $-839,1179$ \\
\hline \multicolumn{13}{|c|}{ Encourage physical activity } \\
\hline A little bit & -643 & $-1408,122$ & -620 & $-1380,140$ & -503 & $-1291,285$ & -719 & $-1977,539$ & -675 & $-1932,582$ & -639 & $-1942,665$ \\
\hline Quite a $\operatorname{lot}^{4}$ & 0 & - & 0 & - & 0 & - & 0 & - & 0 & - & 0 & - \\
\hline Very much & $616^{*}$ & 89,1143 & $632^{*}$ & 108,1155 & 546 & $-33,1126$ & $970^{*}$ & 101, 1839 & $997^{*}$ & 130,1864 & 856 & $-103,1816$ \\
\hline \multicolumn{13}{|c|}{ Engage in physical activity } \\
\hline$<1$ time/week & -8 & $-531,515$ & 19 & $-497,535$ & 222 & $-307,752$ & 409 & $-448,1267$ & 450 & $-402,1303$ & 652 & $-224,1529$ \\
\hline 1-3 times/week ${ }^{4}$ & 0 & - & 0 & - & 0 & - & 0 & - & 0 & - & 0 & - \\
\hline$>4$ time/week & $727^{*}$ & $-103,1558$ & $890^{*}$ & 67,1712 & 712 & $-120,1543$ & 942 & $-420,2304$ & 1161 & $-198,2519$ & 806 & $-571,2183$ \\
\hline $\begin{array}{l}\text { - pedometer-measure } \\
2 \text { - Model } 1 \text { is adjusted } \\
{ }^{3} \text { - Model } 2 \text { is adjusted } \\
\text { parental educational a } \\
4 \text { - reference category. } \\
{ }^{*} \text { - considered statistica }\end{array}$ & $\begin{array}{l}\text { justed } \\
\text { hold ir } \\
\text { al care } \\
\text { and y }\end{array}$ & $\begin{array}{l}\text { for non-ambu } \\
\text { ncome, parenta } \\
\text { about staying } \\
\text { ear of data coll } \\
P<0.05 \text {. }\end{array}$ & $\begin{array}{l}\text { ulatory a } \\
\text { al educa } \\
\text { g fit and } \\
\text { lection. }\end{array}$ & $\begin{array}{l}\text { activities, non-v } \\
\text { tional attainme } \\
\text { exercising, en }\end{array}$ & $\begin{array}{l}\text { Near tim } \\
\text { ent and } \\
\text { courage }\end{array}$ & $\begin{array}{l}\text { activities, a } \\
\text { ear of data } \\
\text { ohysical act }\end{array}$ & miss & data. & . & ather b & ehol & ome, \\
\hline
\end{tabular}


Table 3 The association (beta coefficient and $95 \%$ confidence interval) of parent belief and support with grade five boys' physical activity ${ }^{1}$ on school days and weekend days

\begin{tabular}{|c|c|c|c|c|c|c|c|c|c|c|c|c|}
\hline & \multicolumn{6}{|c|}{ School days } & \multicolumn{6}{|c|}{ Weekend days } \\
\hline & \multirow{2}{*}{\multicolumn{2}{|c|}{ Univariable }} & \multicolumn{4}{|c|}{ Multivariable } & \multirow{2}{*}{\multicolumn{2}{|c|}{ Univariable }} & \multicolumn{4}{|c|}{ Multivariable } \\
\hline & & & \multicolumn{2}{|c|}{ Model $1^{2}$} & \multicolumn{2}{|c|}{ Model $2^{3}$} & & & \multicolumn{2}{|c|}{ Model $1^{2}$} & \multicolumn{2}{|c|}{ Model $2^{3}$} \\
\hline & $\beta$ & $(95 \% \mathrm{Cl})$ & $\beta$ & $(95 \% \mathrm{Cl})$ & $\beta$ & $(95 \% \mathrm{Cl})$ & $\beta$ & $(95 \% \mathrm{Cl})$ & $\beta$ & $(95 \% \mathrm{Cl})$ & $\beta$ & $(95 \% \mathrm{Cl})$ \\
\hline \multicolumn{13}{|c|}{ Care staying fit \& exercising } \\
\hline A little bit & -618 & $-1542,306$ & -654 & $-1582,273$ & -430 & $-1394,534$ & -505 & $-2105,1095$ & -658 & $-2225,910$ & -168 & $-1811,1475$ \\
\hline Quite a $\operatorname{lot}^{4}$ & 0 & - & 0 & - & 0 & - & 0 & - & 0 & - & 0 & - \\
\hline Very much & 505 & $-260,1270$ & 453 & $-316,1222$ & 79 & $-718,877$ & $1439^{*}$ & 121,2758 & $1381^{*}$ & 85,2676 & 1306 & $-50,2661$ \\
\hline \multicolumn{13}{|c|}{ Encourage physical activity } \\
\hline A little bit & -269 & $-1418,880$ & -286 & $-1436,864$ & -165 & $-1358,1028$ & -944 & $-2940,1051$ & -1032 & $-2980,917$ & -563 & $-2570,1445$ \\
\hline Quite a $\operatorname{lot}^{4}$ & 0 & - & 0 & - & 0 & - & 0 & - & 0 & - & 0 & - \\
\hline Very much & $1408^{*}$ & 690,2126 & $1372^{*}$ & 653,2092 & $1373^{*}$ & 606,2139 & 939 & $-322,2201$ & 936 & $-300,2171$ & 625 & $-686,1935$ \\
\hline \multicolumn{13}{|c|}{ Engage in physical activity } \\
\hline$<1$ time/week & -240 & $-971,491$ & -246 & $-973,482$ & 112 & $-641,865$ & $-1680^{*}$ & $-2937,-424$ & $-1669^{*}$ & $-2888,-450$ & $-1367^{*}$ & $-2643,-90$ \\
\hline $1-3$ times/week ${ }^{4}$ & 0 & - & 0 & - & 0 & - & 0 & - & 0 & - & 0 & - \\
\hline >4 time/week & 492 & $-650,1635$ & 566 & $-571,1702$ & 264 & $-882,1410$ & -1276 & $-3254,701$ & -1076 & $-2998,846$ & -1350 & $-3309,608$ \\
\hline
\end{tabular}

1 - pedometer-measured steps adjusted for non-ambulatory activities, non-wear time activities, and missing data.

${ }^{2}$ - Model 1 is adjusted for household income, parental educational attainment and year of data collection.

3 - Model 2 is adjusted for parental care about staying fit and exercising, encourage physical activity, engage in physical activity together, household income, parental educational attainment, and year of data collection.

4 - reference category.

* - considered statistically significant at $\mathrm{P}<0.05$.

There were no significant interactions between parental care for staying fit and exercising, parental encouragement of physical activity, or engagement in physical activity together and girls' "school day/weekend day" step counts. Parental engagement in physical activity and boys' "school day/weekend day" physical activity was the single statistically significant interaction. This interaction remained significant after adjusting for potential confounders. Boys whose parents engaged in physical activity with them less than once per week took 1475 (95\% CI: -2609, -341) fewer steps per day on weekend days than they did on school days.

\section{Discussion}

This study demonstrates the importance of parental beliefs and support for boys' and girls' physical activity on school days and on weekend days. This study demonstrates that parental beliefs and support are important targets for prevention strategies to increase children's physical activity, which is particularly relevant for weekend days, as children's activity levels appear to be low during this window of time.

We confirmed children's physical activity levels to be lower on weekend days than on school days [28-32]. In addition, we observed that parental beliefs and support are positively associated with boys' and girls' physical activity achieved on weekend days. For example, we found that girls whose parents reported to encourage physical activity "very much" were significantly more active on weekend days than girls whose parents reported to encourage physical activity "quite a lot". Similarly, we found that boys whose parents reported to care "very much" about staying fit and exercising were significantly more active on weekend days than boys whose parents reported to care "quite a lot". To our knowledge, this had not been shown in the literature. These results suggest that specifically targeting parents to encourage and support their child's physical activity behaviour may be an effective strategy to improve physical activity.

The associations between parental beliefs and support and weekend day physical activity were distinct for boys and girls. For example, parental encouragement was positively associated with girls' weekend physical activity (Model 1) while parental care for staying fit and exercising was positively associated with boy's weekend physical activity (Model 1). We observed that associations tended to be stronger among boys than girls. McGuire et al. [33] also found that parental-adolescent relationships were stronger among boys than girls. Further, we observed that parents reported to encourage boys to be physically active significantly more than they encouraged girls. Trost et al. [34] found that parents reported significantly higher levels of support and perceived importance for boys' physical activity compared to girls' physical activity. This suggests the importance of health promotion messages that are specific for girls and boys [14], and that educate parents on the importance of physical activity for both boys and girls. Community-based physical 
activity programs occurring on weekends that involve children and their parents may help to increase boys' and girls' physical activity levels on weekends. Health promotion messages should also consider targeting parenting practices as they relate to encouragement to educate parents on how to effectively support their daughters' activity-related behaviours as girls' activity levels lag behind that of boys.

Among boys on the weekend, we found that boys whose parents reported to engage in physical activities with them more than four times per week were less active than boys whose parents reported to engage in activities with them between one and three times per week. This is not supported in the literature; others report positive associations between parental engagement in activities and children's physical activity [6,8-11]. The finding we report here is counter intuitive and may be a result of reverse causation, meaning these parents have recognized their sons to be in a less active subgroup and are intervening in an attempt to raise their activity levels. This seems consistent with our earlier observations, though in a different sample of children, where parents engaged more in activity with their overweight daughters or sons than with their normal weight children [11]. This is an interesting point and warrants further investigation.

Strengths of our study include the use of timestamped pedometers, a large sample size, and high participation rates for school-based research [35]. A further strength of our study is the adjustments made to raw pedometer-measured steps from activities recorded by students in daily activity logs. There are a few limitations however, that should be acknowledged. Although selected from a population-based sample, the sample of students in this study is not representative of the Alberta population. As such, caution is warranted when generalizing the present results. The cross-sectional design is a limitation and necessitates caution with respect to interpretations of directionality and causality. Furthermore, while the pedometer used in this study has been validated among adults under various conditions [17-19], it has not specifically been validated among $10-11$ yearold children. However, because all children wore the same pedometer it is unlikely that this influenced the observed effect size [36]. Also, self-report measures are prone to bias and may produce socially desirable responses to questions surrounding parental beliefs and support. This limitation is acknowledged in the literature [37]. Additionally, given that we did not quantify "how much" parents encourage their child to be active, it is possible that broader parenting practices or styles were captured rather than the actual encouragement itself [38]. This warrants further investigation. To better inform health promotion messages and interventions, future studies may also consider assessing differences in the provisions of encouragement, engagement, and care between boys and girls.

\section{Conclusions}

We showed that parental beliefs and support for physical activity are associated with children's physical activity on school days and on weekend days. Health promotion strategies and programs that educate parents on how to effectively support their child in developing an active lifestyle may contribute to increasing physical activity levels.

\section{Abbreviations}

REAL Kids Alberta: Raising healthy eating active living kids Alberta.

\section{Competing interests}

The authors declare that they have no competing interests.

\section{Authors' contributions}

KV assisted with data collection, analyzed and interpreted the data, and drafted the manuscript. SK, KM, JM, BW interpreted the data and critically revised the manuscript. PV conceived and designed the study, interpreted the data, and critically revised the manuscript. All authors read and approved the final version.

\section{Acknowledgements}

We thank all grade five students, parents and schools for their participation. We also thank the evaluation assistants for the execution of the data collection and Connie Lu for data management and validation. The REAL Kids Alberta evaluation is funded through a contract with Alberta Health and Wellness. The present research is funded through a Canada Research Chair in Population Health and Alberta Innovates Health Solutions Health Scholarship to Dr. Paul J. Veugelers.

\section{Author details}

${ }^{1}$ School of Public Health, University of Alberta, Edmonton Alberta, Canada. ${ }^{2}$ Departments of Pediatrics and Obstetrics \& Gynecology, Dalhousie University, Halifax, Nova Scotia, Canada. ${ }^{3}$ Department of Pediatrics and Child Health, University of Manitoba, Winnipeg, Manitoba, Canada.

Received: 21 February 2013 Accepted: 27 November 2013 Published: 5 December 2013

\section{References}

1. Janssen I, Leblanc AG: Systematic review of the health benefits of physical activity and fitness in school-aged children and youth. Int J Behav Nutr Phys Act 2010, 7:40.

2. Colley RC, Garriguet D, Janssen I, Craig CL, Clarke J, Tremblay MS: Physical activity of Canadian children and youth: accelerometer results from the 2007 to 2009 Canadian Health Measures Survey. Health Rep 2011, 22:15-23.

3. Vander Ploeg KA, Wu B, McGavock J, Veugelers PJ: Physical activity among Canadian children on school days and nonschool days. J Phys Act Health 2012, 9:1138-1145.

4. Krebs NF, Himes JH, Jacobson D, Nicklas TA, Guilday P, Styne D: Assessment of child and adolescent overweight and obesity. Pediatr 2007, 120(Suppl 4):S193-S228.

5. Brustad RJ: Who Will Go Out and Play? Parental and psychological influences on children's attraction to physical activity. Pediatr Exerc Sci 1993, 5:210-223.

6. Prochaska JJ, Rodgers MW, Sallis JF: Association of parent and peer support with adolescent physical activity. Res Q Exerc Sport 2002, 73:206-210.

7. Sallis JF, Prochaska JJ, Taylor WC: A review of correlates of physical activity of children and adolescents. Med Sci Sports Exerc 2000, 32:963-975.

8. Duncan SC, Duncan TE, Strycker LA: Sources and types of social support in youth physical activity. Health Psychol 2005, 24:3-10. 
9. Moore LL, Lombardi DA, White MJ, Campbell $L$, Oliveria SA, Ellison RC: Influence of parents' physical activity levels on activity levels of young children. J Pediatr 1991, 118:215-219.

10. Sallis JF, Alcaraz JE, McKenzie TL, Hovell MF, Kolody B, Nader PR: Parental behavior in relation to physical activity and fitness in 9-year-old children. Am J Dis Child 1992, 146:1383-1388.

11. Vander Ploeg KA, Maximova K, Kuhle S, Simen-Kapeu A, Veugelers PJ: The importance of parental beliefs and support for physical activity and body weights of children: a population-based analysis. Can J Public Health 2012, 103:e277-e281.

12. Jones RA, Hinkley T, Okely AD, Salmon J: Tracking physical activity and sedentary behavior in childhood: a systematic review. Am J Prev Med 2013, 44:651-658.

13. Telama R: Tracking of physical activity from childhood to adulthood: a review. Obes Facts 2009, 2:187-195.

14. Simen-Kapeu A, Veugelers PJ: Should public health interventions aimed at reducing childhood overweight and obesity be gender-focused? BMC Public Health 2010, 10:340.

15. Fung C, Kuhle S, Lu C, Purcell M, Schwartz M, Storey K, Veugelers PJ: From "best practice" to "next practice": the effectiveness of school-based health promotion in improving healthy eating and physical activity and preventing childhood obesity. Int J Behav Nutr Phys Act 2012, 9:27.

16. Davison KK, Cutting TM, Birch LL: Parents' activity-related parenting practices predict girls' physical activity. Med Sci Sports Exerc 2003, 35:1589-1595.

17. Hasson R, Haller J, Pober D, Staudenmayer J, Freedson P: Validity of the Omron HJ-112 pedometer during treadmill walking. Med Sci Sports Exerc 2009, 41:805.

18. Holbrook E, Barreira T, Kang M: Validity and reliability of Omron pedometers for prescribed and self-paced walking. Med Sci Sports Exerc 2009, 41:670.

19. Zhu W, Lee M: Invariance of wearing location of Omron-BI pedometers: a validation study. J Phys Act Health 2010, 7:706.

20. Cole TJ, Bellizzi MC, Flegal KM, Dietz WH: Establishing a standard definition for child overweight and obesity worldwide: international survey. BMJ 2000, 320:1240-1243.

21. Penpraze V, Reilly JJ, MacLean CM, Montgomery C, Kelly LA: Monitoring of physical activity in young children: how much is enough? Pediatr Exerc Sci 2006, 18:483-491.

22. Craig CL, Tudor-Locke C, Cragg S, Cameron C: Process and treatment of pedometer data collection for youth: the Canadian Physical Activity Levels among Youth study. Med Sci Sports Exerc 2010, 42:430-435.

23. Ridley $\mathrm{K}$, Ainsworth BE, Olds TS: Development of a compendium of energy expenditures for youth. Int J Behav Nutr Phys Act 2008, 5:45.

24. Ainsworth BE, Haskell WL, Whitt MC, Irwin ML, Swartz AM, Strath SJ, Brien WILLIAML O, Bassett DAVIDR, Schmitz KH, Emplaincourt PO: Compendium of physical activities: an update of activity codes and MET intensities. Med Sci Sports Exerc 2000, 32:S498-S504.

25. Trost SG, Pate RR, Freedson PS, Sallis JF, Taylor WC: Using objective physical activity measures with youth: how many days of monitoring are needed? Med Sci Sports Exerc 2000, 32:426-431.

26. Jago R, Watson K, Baranowski T, Zakeri I, Yoo S, Baranowski J, Conry K: Pedometer reliability, validity and daily activity targets among 10- to 15-year-old boys. J Sports Sci 2006, 24:241-251.

27. Kang M, Rowe DA, Barreira TV, Robinson TS, Mahar MT: Individual information-centered approach for handling physical activity missing data. Res Q Exerc Sport 2009, 80:131-137.

28. Duncan MJ, Al-Nakeeb Y, Woodfield L, Lyons M: Pedometer determined physical activity levels in primary school children from central England. Prev Med 2007, 44:416-420

29. McGall SE, McGuigan MR, Nottle C: Contribution of free play towards physical activity guidelines for New Zealand primary school children aged 7-9 years. Br J Sports Med 2011, 45:120-124.

30. Nyberg GA, Nordenfelt AM, Ekelund U, Marcus C: Physical activity patterns measured by accelerometry in 6- to 10 -yr-old children. Med Sci Sports Exerc 2009, 41:1842-1848.

31. Rowe DA, Mahar MT, Raedeke TD, Lore J: Measuring physical activity in children with pedometers: Reliability, reactivity, and replacement of missing data. Pediatr Exerc Sci 2004, 16:343-354.

32. Rowlands AV, Pilgrim EL, Eston RG: Patterns of habitual activity across weekdays and weekend days in 9-11-year-old children. Prev Med 2008 46:317-324.
33. McGuire MT, Hannan PJ, Neumark-Sztainer D, Cossrow NH, Story M: Parental correlates of physical activity in a racially/ethnically diverse adolescent sample. J Adolesc Health 2002, 30:253-261.

34. Trost SG, Sallis JF, Pate RR, Freedson PS, Taylor WC, Dowda M: Evaluating a model of parental influence on youth physical activity. Am J Prev Med 2003, 25:277-282.

35. Finn-Aage E, Melde C, Taylor TJ, Peterson D: Active parental consent in school-based research: how much is enough and how do we get it. Eval Rev 2008, 32:335-362.

36. Rothman KJ, Greenland S, Lash TL: Modern Epidemiology. Thirdth edition. Philadelphia, PA: Lippincott Williams \& Wilkins; 2008.

37. Baranowski T, O'Connor T, Hughes S, Sleddens E, Beltran A, Frankel L, Mendoza JA, Baranowski J: Houston. We have a problem! Measurement of parenting. Child Obes 2013, 9(S1):S1-S4.

38. Trost SG, McDonald S, Cohen A: Measurement of general and specific approaches to physical activity parenting: a systematic review. Child Obes 2013, 9(Suppl):S40-S50.

doi:10.1186/1471-2458-13-1132

Cite this article as: Vander Ploeg et al:: The importance of parental beliefs and support for pedometer-measured physical activity on school days and weekend days among Canadian children. BMC Public Health 2013 13:1132.

\section{Submit your next manuscript to BioMed Central and take full advantage of:}

- Convenient online submission

- Thorough peer review

- No space constraints or color figure charges

- Immediate publication on acceptance

- Inclusion in PubMed, CAS, Scopus and Google Scholar

- Research which is freely available for redistribution

Submit your manuscript at www.biomedcentral.com/submit
C Biomed Central 